\title{
Coerência referencial e ordem oracional
}

\section{Referential coherence and order of clauses}

\author{
Sávio André de Souza Cavalcante ${ }^{1}$ \\ Márluce Coan ${ }^{2}$
}

\begin{abstract}
Resumo: Tomando por base o fenômeno da coerência referencial tal como entendido por Givón (1995; 2001b), analisamos suas consequências sintáticas na combinação de cláusulas. Com apoio em teorias funcionalistas que defendem a articulação de cláusulas em termos de gradiência (HAIMAN; THOMPSON, 1984; HOPPER; TRAUGOTT, 2003; GIVÓN, 2001b), descrevemos e analisamos 596 Cláusulas Hipotáticas Temporais do Corpus Sociolingüístico de la Ciudad de México (CSCM) e testamos a hipótese de Givón (1995; 2001b) sobre continuidade referencial em cláusulas mais integradas às que se articulam, observando a posição (anteposta, intercalada, posposta), seu tipo (desenvolvida, reduzida) e seus sujeitos (correferenciais ou não aos de suas nucleares). Nossos resultados mostram a atuação do princípio de marcação e sua dependência ao contexto (GIVÓN, 1995; 2001a) e do princípio de expressividade (DUBOIS; VOTRE, 2012), principalmente no uso de cláusulas intercaladas, formas menos marcadas nesse contexto, por expressarem maior coerência referencial do que as antepostas e pospostas. Concluímos que a combinação de orações serve a propósitos discursivos, mobilizando a coerência referencial no discurso, cujos meios sintáticos são expressos em cláusulas mais integradas à sua nuclear.
\end{abstract}

Palavras-chave: Coerência referencial. Ordem oracional. Cláusulas Hipotáticas Temporais. Funcionalismo norte-americano.

\begin{abstract}
Based on the phenomenon of referential coherence as understood by Givón (1995; 2001b), we analyzed its syntactic consequences in the combination of clauses. Supported by functionalist theories that defend the articulation of clauses in terms of gradience (HAIMAN; THOMPSON, 1984; HOPPER; TRAUGOTT, 2003; GIVÓN, 2001b), we described and analyzed 596 Temporal Hypotactic Clauses of the Corpus Sociolingüístico de la Ciudad de México (CSCM) and we tested Givón (1995; 2001b)'s hypotheses regarding the greater referential continuity of clauses more integrated to those to which they are articulated. We observed the position of the clause (preposed, interpolated, postposed), its type (developed, reduced), and its subject (coreferential or non-coreferential to the nuclear clause's subject). Our results show the role of the markedness principle along with its dependence on context (GIVÓN, 1995; 2001a) and the principle of expressiveness (DUBOIS; VOTRE, 2012) in the use of interpolated sentences, which are less marked forms in this context, as they express greater referential coherence than preposed and postposed clauses. We conclude that the combination of clauses has discursive purposes, mobilizing the discourse referential coherence, whose syntactic means are expressed in clauses more integrated to their sentential nucleus.
\end{abstract}

Keywords: Referential coherence. Order of clauses. Temporal Circumstantial Hypotatic Clauses. North American functionalism.

\footnotetext{
${ }^{1}$ Instituto Federal de Educação, Ciência e Tecnologia do Ceará, Fortaleza, CE, Brasil. Endereço eletrônico: savio.andre@ifce.edu.br.

${ }^{2}$ Universidade Federal do Ceará, Centro de Humanidades, Departamento de Letras Vernáculas, Fortaleza, CE, Brasil. Endereço eletrônico: coanmalu@ufc.br.
} 


\section{Introdução}

Dentre os aspectos que pautam a combinação oracional estão, na visão de Givón (1995; 2001b), os relacionados à coerência interoracional, mecanismo que permite a continuidade discursiva dos enunciados $\operatorname{conectados}^{3}$. O autor explica que não é possível haver independência contextual de cláusulas em um discurso articulado e que essa coerência discursiva sempre apresentará consequências gramaticais.

Entre os meios sintáticos de gerenciamento da continuidade referencial, ressaltamos a ordem de Cláusulas Temporais em relação às suas respectivas nucleares, estratégia empregada pelo falante para o encaminhamento de seus objetivos comunicativos por meio da codificação de distintas funções textual-discursivas, como vemos em (01) a (03):

(01) 31 I: sí/ todavía/ y habitualmente cuando/l pues no sé/ cuando < cuando:>/ termina uno de comer/ ah/ pues no sél tienes/ tres cuatro/ cinco personas/ y pues no te da tanta flojeral ¿verdad? < verdá>// y y cuando yo llegué/ cuando tenía seis años/llegando llegando en la terminal estel por ahí < ai>/ nos paramos a/ a comer algo/ y entonces/ cuando yo terminé mel me < me:>/ hinqué en una de las sillas y me puse a ver toda $<\sim$ to:da> la gente que había ahí/ ¿no?/

(31 I: sim/ ainda/ e habitualmente quando// pois não sei/ quando alguém termina de comer/ ah/ pois não sei/ tens/ três quatro/ cinco pessoas/ e pois não te dá tanta molezal verdade?// e e quando eu cheguei/ quando tinha seis anos/chegando chegando ao terminal estel por aíl paramos a/ a comer algol e então/ quando eu terminei mel mel finquei em uma das cadeiras e comecei a ver toda as pessoas que havia aíl não?/). (ENTREVISTA 55 - ME110-22M-00).

(02) ... sí/ yo también cuando la conocíl pensé que era más joven//(...).

( $\mathrm{sim} /$ eu também quando a conheci/ pensei que era mais jovem// (...)). (ENTREVISTA 7 - ME-107-31M-00).

\footnotetext{
${ }^{3}$ Admitimos o postulado da relação entre coerência e coesão, embora sem limites precisos, porque "a coerência é estabelecida a partir da sequência linguística que constitui o texto, isto é, os elementos da superfície linguística é que servem de pistas, de ponto de partida para o estabelecimento da coerência. A coesão ajuda a estabelecer a coerência na interpretação dos textos, porque surge como uma manifestação superficial da coerência no processo de produção dos mesmos textos" (KOCH; TRAVAGLIA, 2015, p. 49). Neste trabalho, entretanto, adotamos a proposta de Givón $(1995 ;$ 2001b), tendo em vista as reflexões do autor sobre os aspectos da continuidade discursiva e posição de orações, ponto de partida das hipóteses desta pesquisa.
} 
(03) $496 \mathrm{I}:$... en cambio/ en los nietos/ todo lo que hacen es gracia// ya se me olvidó lo que hacían los niños/ cuando empiezan a hablar// ves cómo empiezan a estructurar las palabras/ y te mueres de emoción/ de cómo van// formando su cerebrito.

(496 I: ... ao contrário/ quanto aos netos/ todo o que fazen é graça// eu já me esqueci do que faziam as crianças/ quando começam a falar// você vê como começam a estruturar as palavras/ e você morre de emoção/ de como vão// formando seu cerebrinho). (ENTREVISTA $31-$ ME220-33M-02).

Nos exemplos apresentados, vemos, respectivamente, anteposição, intercalação e posposição de Cláusulas Temporais. Entre as várias cláusulas em (01), destacamos duas: cuando termina uno de comer (quando alguém termina de comer) e llegando en la terminal (chegando ao terminal), respectivamente, uma cláusula desenvolvida e uma reduzida. Iniciando um novo turno, o falante introduz uma Temporal com o pronome indefinido uno (alguém) trazendo um caráter de genericidade. À medida que prossegue, instaura a primeira pessoa por meio do pronome pessoal yo $(e u)$, retomando-o nas cláusulas subsequentes.

Em (02), a Temporal cuando la conocí (quando a conheci) retoma o sujeito de primeira pessoa da nuclear à que se integra, sem marca pronominal. No trecho (03), a continuidade referencial também se observa, dessa vez com cuando empiezan a hablar (quando começam a falar). Em ambos, o sujeito se apresenta como correferencial ao da nuclear, o que não ocorre na primeira Temporal anteposta em (01).

Dessas observações, notamos que as cláusulas antepostas que iniciam turnos de fala parecem mais integradas às porções de texto anteriores, enquanto as intercaladas e as pospostas sugerem maior integração à sua cláusula nuclear. Em face dessa discussão, objetivamos analisar a coerência referencial codificada na posição de Orações Temporais, investigando a correferencialidade entre seus sujeitos e os de suas respectivas nucleares (identidade de elementos) e o tipo de oração, desenvolvida ou reduzida (compartilhamento de tempo-aspecto-modalidade com a nuclear pela redução de finitude). A análise aqui proposta tem como norte teórico a noção de coerência referencial (GIVÓN, 1995; 2001a; 2001b) e os princípios de marcação (GIVÓN, 1995; 2001a) e expressividade (DUBOIS; VOTRE, 2012).

$\mathrm{Na}$ próxima seção, tratamos de coerência referencial, seguindo-se seção sobre as cláusulas hipotáticas adverbiais, pois a continuidade (ou não) de elementos no discurso implica opções de ordenação ou, por prisma inverso (porém articulado), a ordenação de uma cláusula adverbial em relação a sua nuclear repercute na coerência referencial. Ordenação e correferencialidade refletem, portanto, marcação e expressividade, princípios que abordamos 
na terceira seção teórica deste artigo e dos quais emergem nossas hipóteses. Seguem-se metodologia, análise e conclusões. Na metodologia, além da apresentação do corpus, explicitamos os parâmetros analíticos e expomos nossa opção pelo viés quantitativo. Essas etapas metodológicas culminam em análise que correlaciona resultados estatísticos aos pressupostos teóricos.

\section{Coerência referencial}

A coerência é definida por Givón (2001b) como a continuidade ou recorrência de elemento(s) em porções do discurso. Entre os elementos que podem expressar a coerência estão os referentes, entidades evocadas pelos falantes, em seu intento referencial, cujos efeitos na língua apontam para a coerência referencial. Segundo o mesmo autor, na articulação entre as cláusulas adverbiais e suas respectivas nucleares, a posição em que aquelas se apresentam revela aspectos da coerência referencial que delas emerge (GIVÓN, 2001b).

O autor, retomando Thompson (1985) e Ramsay (1987), conclui que cláusulas adverbiais pospostas teriam uma conectividade mais estrita às suas nucleares, apresentando sujeito correferencial, como no exemplo (03). Isso apontaria, sintaticamente, para um maior grau de integração entre essas cláusulas, o que se percebe, também, pela ausência de pausa. Já as adverbiais antepostas, voltando-se a cadeias, parágrafos ou episódios antecedentes, teriam um escopo mais amplo e difuso, não restrito à sua nuclear, inclusive separando-se dela por pausa. Como consequência, Givón $(1995 ; 2001 b)$ distribui as pospostas em contexto de alta continuidade temática, refletindo coerência mais local, e as antepostas, em contexto de alta descontinuidade temática, apontando para maior coerência global. A proposta do autor, no entanto, não especifica o escopo dos termos anteposição e posposição, ao que concluímos que se trata da posição em relação à nuclear, embora também possa se referir a posições pré e pósverbais, critério depreendido de Olivares Pardo (2002) ao tratar de ordem de orações. Os resultados apontados pelo pesquisador também não mencionam as estruturas intercaladas prototípicas (CAVALCANTE, 2020), inseridas entre verbo e seus argumentos/circunstantes.

Outra consequência sintática da continuidade discursiva é a tendência à não expressão do sujeito correferencial. Estudos como o de Silva-Corvalán (2003) comprovam que, em distintas variedades do Espanhol, a expressão dos sujeitos não correferenciais ocorre em 50\% dos dados contra 25\% de expressão de sujeitos correferenciais. Observando apenas os casos de sujeito explícito, Manjón-Cabeza Cruz et al. (2016) perceberam que a correferencialidade motiva mais a aparição do sujeito quando se relaciona a qualquer elemento da cláusula anterior (peso 0.560) do que ao próprio sujeito precedente (peso 0.469). 
Desse modo, com os devidos ajustes, objetivamos aplicar as conclusões de Givón (2001b) à análise da ordem de Cláusulas Temporais, tomando por base a hipótese de que as pospostas e as intercaladas, por apresentarem um escopo mais restrito à sua nuclear, teriam maior índice de codificação da coerência referencial por meio da correferencialidade dos sujeitos, enquanto as antepostas apresentariam menor frequência de sujeitos equivalentes aos de suas nucleares, estabelecendo coerência mais global. Por acreditarmos que o processamento da língua advém de pressões de distintos domínios, essas hipóteses precisam ser relacionadas, também, à manifestação da Cláusula Temporal, que pode se apresentar em forma finita ou não-finita (desenvolvida ou reduzida), como veremos na seção seguinte.

\section{As Cláusulas Hipotáticas Circunstanciais Temporais}

A tradição gramatical opõe orações coordenadas e subordinadas a partir do critério da dependência, postulando que as coordenadas são independentes e autônomas, enquanto as subordinadas seriam dependentes e, portanto, sem autonomia gramatical. Por outro lado, a visão funcionalista que norteia este texto considera a articulação oracional como uma questão de grau (HAIMAN; THOMPSON, 1984; HOPPER; TRAUGOTT, 2003; GIVÓN, 2001b etc.), partindo da tríade parataxe-hipotaxe-subordinação (HOPPER; TRAUGOTT, 2003). A hipotaxe denota interdependência entre as cláusulas (HOPPER; TRAUGOTT, 2003), já que, por não funcionarem como argumentos verbais, não seriam dotadas do traço encaixamento, mas, por veicularem noções semânticas de elaboração (relativas apositivas) ou de realce (adverbiais) (HALLIDAY, 2004[1985]), guardariam certa dependência.

Entre as Cláusulas Hipotáticas de realce, encontram-se as Temporais, que expandem o sentido de suas correspondentes nucleares, apresentando noção circunstancial de tempo. Essas cláusulas podem ter seu verbo em forma finita, como em (02) e (03), apresentando variados conectores ${ }^{4}$ (PILAR GARCÉS, 1994), entre os quais o cuando (quando) é o mais prototípico.

Os enunciados de tempo também podem ser codificados por meio de orações nãofinitas (reduzidas), como em llegando en la terminal (chegando ao terminal), no exemplo (01), cuja noção temporal pode ser recuperada por meio de interpretações plausíveis, fatores contextuais, relação falante/ouvinte e temática abordada no texto específico (FORD, 1987).

\footnotetext{
${ }^{4}$ A saber: cuando, mientras (que), mientras tanto, entretanto que, en tanto que, en el (mismo, preciso) momento (instante) en que, a medida que, a la vez que, al (mismo) tiempo que, siempre que, cada vez que, antes de que, antes de, una vez que, después (de) que, después de, luego que, en cuanto, tan pronto como, apenas, así que, desde que, hasta que [quando, enquanto, enquanto isso, enquanto, enquanto, no (mesmo, preciso) momento (instante) em que, à medida que, ao mesmo tempo que, ao (mesmo) tempo que, sempre que, cada vez que, antes que, antes de, uma vez que, depois (de) que, depois de, assim que, enquanto/quando, assim que/logo que/tão logo que, mal, assim que, desde que, até que].
} 
Segundo Bakhtin (2013), o uso de orações reduzidas, como em (01), está diretamente conectado à manifestação de traços expressivos individuais dos falantes. Nesse token, a cláusula sofreu um processo de dessentencialização (LEHMANN, 1988), com a perda da finitude do verbo e do referente sujeito, tendo, em sua leitura, sujeito, tempo e aspecto contextuais (MACAMBIRA, 1971; CAVALCANTE, 2017). Nesse sentido, hipotetizamos que as temporais reduzidas seriam, em sua maioria, intercaladas ou pospostas, contribuindo ativamente para a continuidade referencial do período em que estão inseridas, apontando para aspectos mais expressivos que o mero uso de conectores subordinativos.

Se as Cláusulas Hipotáticas Circunstanciais Temporais têm mobilidade na estrutura, ou seja, podem estar antepostas, pospostas ou intercaladas, a opção por uma ou outra ordenação decorre de motivações que refletem princípios cognitivos, como os de marcação e expressividade por exemplo, sobre os quais tecemos considerações na sequência.

\section{Marcação e expressividade}

Uma noção que relaciona a codificação linguística a estratégias cognitivas é a marcação. Segundo Givón (1995; 2001a), esse fenômeno é sensivelmente motivado pelo contexto e mensurado por três critérios: complexidade estrutural, distribuição de frequência e complexidade cognitiva, este último avaliado quanto a esforço mental, demanda de atenção e tempo de processamento. Avaliada sob esses parâmetros, a categoria marcada seria mais complexa estruturalmente, menos frequente e mais complexa cognitivamente que sua correspondente não marcada (GIVÓN, 1995; 2001a).

Furtado da Cunha, Costa e Cezario (2003) preferem avaliar marcação não em perspectiva binária, mas escalar, e Cavalcante (2020) manuseia o critério de complexidade estrutural não apenas como aumento de forma, mas na ocorrência de qualquer padrão estrutural não canônico. Outra revisão é a proposta de Dubois; Votre (2012), em que os autores discutem o equilíbrio das tarefas de codificação, propondo o princípio de expressividade, sugerindo que determinado fenômeno linguístico marcado pode ser menos complexo estruturalmente e cognitivamente e mais frequente. Acreditamos que as assunções dos autores refletem a dependência da marcação ao contexto (GIVÓN, 1995; 2001a).

Nesse sentido, consideramos as seguintes hipóteses quanto à marcação das variáveis analisadas neste estudo, tendo em conta que o contexto de continuidade referencial, por ser menos marcado (GIVÓN, 1995), atrairia formas menos marcadas: 
- Deveria haver abundância de orações Temporais antepostas, menos marcadas quanto à complexidade cognitiva (pela função de guia) e por sua alta frequência (cf. CAVALCANTE, 2015); e de orações Temporais pospostas, menos marcadas quanto à complexidade estrutural, mais frequentes que as intercaladas. No entanto, considerando a assunção de Givón (2001b) quanto à coerência global das antepostas e mais local das pospostas (e, por inferência, das intercaladas), seriam utilizadas formas mais marcadas que a anteposição, como a posposição e a intercalação, por ser mais icônico retomar um referente, ou seja, estabelecer uma relação anafórica entre o referente e o termo que o retoma, do que apelar para a coerência global (a parágrafos ou episódios antecedentes, cujo escopo seria mais difuso) ou para uma relação catafórica. Observamos, assim, a dependência da marcação ao contexto (GIVÓN, 1995, 2001a) e o princípio de expressividade (DUBOIS; VOTRE, 2012);

- Tal contexto, menos marcado, também deveria atrair cláusulas finitas, desenvolvidas, formas menos marcadas (GIVÓN, 1995; ANDERSEN, 2001). Contudo, mais uma vez considerando marcação dependente de contexto (GIVÓN, 1995, 2001a) e o princípio de expressividade (DUBOIS; VOTRE, 2012), as reduzidas, cláusulas não-finitas, deveriam ser as mais comuns nessas situações, já que, no discurso conectado, tendem a refletir compartilhamento de sujeito, tempo, aspecto e modalidade (MACAMBIRA, 1971; GIVÓN, 1995; CAVALCANTE, 2017), imprimindo maior subjetividade (BAKHTIN, 2013);

- Relacionando as hipóteses anteriores, postulamos que, nesse contexto menos marcado, predominaria a correferencialidade dos sujeitos, principalmente codificados pelas formas não marcadas da pronominalização e/ou anáfora zero (GIVÓN, 1995).

Em face das exigências de cruzamentos entre as variáveis, o atendimento aos princípios de marcação (GIVÓN, 1995, 2001a) e de expressividade (DUBOIS; VOTRE, 2012) sempre deve ser observado em contexto, e, por isso, suas motivações serão descritas ao longo da análise dos dados. Antes, porém, vejamos os procedimentos metodológicos adotados.

\section{Metodologia}

Esta pesquisa, quanto ao método de abordagem, tem orientação abdutiva (GIVÓN, 1995), o que nos permite formular hipóteses e ratificá-las ou não ao longo da observação dos dados. No que diz respeito ao tipo, a investigação tem cunho descritivo e explicativo (GIL, 2008), por tratar de um fenômeno observado na língua em uso e por buscar explicações teóricas para as diferentes estratégias de ordenação descritas. 
Nosso universo de pesquisa é composto pela análise de 36 entrevistas do Corpus Sociolingüístico de la Ciudad de México (CSCM) ${ }^{5}$, que reúne inquéritos de residentes da região denominada Zona Pertinente (ZP), de 27 entidades do estado mexicano. O número de entrevistas advém da organização estratificada das seguintes células sociais: 3 faixas etárias (jovens: 20-34 anos; adultos: 35-54 anos; idosos: maiores de 55 anos) X 3 níveis de escolaridade (alto, médio e baixo) X 4 informantes por célula. Apesar de incluir os fatores faixa etária e escolaridade, não é nossa intenção verificar a atuação dessas variáveis e sua relação com a coerência referencial subjacente à posição das orações, mas minimizar um falso viés dos resultados (GUY; ZILLES, 2007).

Nossa opção pelo corpus citado leva em consideração critérios elencados por Sardinha (2004): (i) autenticidade (composto por situações de uso da língua); (ii) atualidade (entrevistas coletadas entre 1997 e 2007); (iii) extensão (contém cerca de 1.500 .000 palavras, classificado como médio-grande); (iv) representatividade (reúne informantes de 27 entidades do Estado do México) e (v) organização/formatação (construído sob rigor metodológico de orientação sociolinguística e legível por computadores). Além desses aspectos, o banco de dados possibilita o acesso completo às entrevistas, característica crucial para o mapeamento de estruturas temporais canônicas e não canônicas.

Após a coleta das Cláusulas Temporais (antepostas, intercaladas e pospostas), codificamos cada dado segundo o tipo de cláusula (desenvolvida ou reduzida) e a correferencialidade entre seus sujeitos e os de suas respectivas nucleares (correferencial ou não correferencial). Entre os dados descartados, incluímos as Temporais cujas nucleares não puderam ser recuperadas cotextualmente, as que não podiam ter sua posição comutada e, apenas no grupo correferencialidade, os dados de oração sem sujeito.

Concluída a etapa de coleta e codificação dos dados, realizamos tratamento estatístico com o auxílio do software GOLDVARB X, que calcula frequências e pesos relativos ${ }^{6}$, medidas úteis para entender o curso dos fenômenos linguísticos (GUY; ZILLES, 2007). Por isso, a pesquisa também se enquadra no tipo qualitativo-quantitativo (RICHARDSON et al., 2012), não apenas observando ocorrências quantificadas, mas regularidades atestadas em dados individuais ou em categorias de dados.

\footnotetext{
${ }^{5}$ Disponível em: https://lef.colmex.mx/corpus_sociolinguistico.html. Acesso em: 10 mai. 2020.

6 "O peso de um fator é um valor calculado pelo Varbrul (com base em um conjunto de dados) que indica o efeito deste fator sobre o uso da variante investigada neste conjunto. $\mathrm{O}$ valor dos pesos recai sempre no intervalo entre zero e um (0-1), em que um valor de zero indica que tal variante nunca acontece quando este fator está presente, e um valor de um indica que tal variante sempre ocorre quando o fator está presente" (GUY; ZILLES, 2007 , p. 239, grifos dos autores). Em geral, consideramos que valores acima do ponto neutro (>0.5) favorecem a aplicação da regra, enquanto os valores abaixo $(<0.5)$ desfavorecem.
} 
Tendo em vista a não binariedade da variável dependente ordem de orações, optamos por realizar três rodadas estatísticas, que relacionam, respectivamente, (i) anteposição $e$ posposição, (ii) intercalação e anteposição e (iii) posposição e intercalação. Passemos, então, à apresentação e discussão dos resultados.

\section{Coerência referencial e ordem de orações I - Anteposição versus posposição}

Em primeiro lugar, apresentamos os resultados gerais que dizem respeito às posições oracionais aqui analisadas. A tabela 01 revela maior concentração de Temporais às margens do período (anteposição: $57.7 \%$ e posposição: 25.3\%), em rechaço aos mecanismos que propiciam a descontinuidade da nuclear (intercalação: 17\%):

Tabela 01 - Ordem de Orações Temporais no Espanhol Mexicano Oral

$\begin{array}{ccc}\text { Fatores } & \% & \text { Aplicação/Total } \\ \text { Anteposição } & 57.7 & 344 / 596 \\ \text { Posposição } & 25.3 & 151 / 596 \\ \text { Intercalação } & 17 & 101 / 596 \\ & \text { Total } & \mathbf{5 9 6} \text { ocorrências }\end{array}$

Fonte: elaborada pelos autores.

Segundo Cavalcante (2015), a anteposição é a posição menos marcada do ponto de vista da alta frequência e da baixa complexidade cognitiva, já que, por ser lugar propício à expressão da função de guia, apresenta os fatos para o entendimento de toda a cena narrada na cláusula nuclear. Acreditamos que, por expressarem coerência mais global (GIVÓN, 1995, 2001b), as antepostas são uma espécie de repositório de informação anafórica, construídas a partir do que vinha se desenvolvendo em períodos anteriores, e articulam-se à porção seguinte do texto, constituindo-se em pontes de coerência (GIVÓN, 2001b)/ pontes de transição (DECAT, 2001). Ainda segundo Cavalcante (2015), as pospostas atenderiam ao padrão canônico esperado para os elementos circunstanciais, emoldurando/ realçando/ avaliando os fatos já apresentados, instituindo coerência local (GIVÓN, 1995, 2001a). Em último lugar no quesito frequência, ficam as intercaladas, segundo Cavalcante (2015), as mais complexas estruturalmente e cognitivamente, tendo sido esse último aspecto rediscutido por Cavalcante (2020), pois

O enunciador intercala não para carregar sua sentença de complexidade, mas, pelo contrário, para reduzir a complexidade da interpretação, adicionando o máximo de informações que puder, para que a comunicação linguística tenha maior eficácia e alcance seus propósitos (CAVALCANTE, 2020, p. 118). 
Ainda que atuem na manutenção da coerência local e continuidade discursiva, as intercaladas, além de representarem uma quebra no padrão canônico de disposição dos termos na sentença, são inseridas entre termos aderidos entre si. Esses dois mecanismos ferem, respectivamente, o princípio de integridade de domínio $^{7}$ (DIK, 1997) e regras de espaçamento $^{8}$ (GIVÓN, 2001a).

Em relação às rodadas estatísticas, como dissemos, foram feitas três análises, cujos resultados passamos a discutir. Em primeira análise, apenas com dados de anteposição e posposição (495 ocorrências), os grupos escolhidos não foram considerados relevantes pelo software estatístico. Por isso, apresentaremos apenas percentuais, que não revelam motivações, mas apenas tendências de uso:

Tabela 02 - Correferencialidade dos sujeitos e anteposição versus posposição

\section{Fatores}

Sujeitos correferenciais

Sujeitos

não correferenciais

\section{Anteposição}

69.4

67.2

\section{Posposição \\ 30.6}

32.8

\begin{tabular}{cc}
\multicolumn{2}{c}{ Aplicação/Total } \\
Anteposição & Posposição \\
$127 / 183$ & $56 / 183$ \\
$133 / 198$ & $65 / 198$
\end{tabular}

$260(68.2 \%)$
$121(31.8 \%)$

Totais

381 ocorrências ${ }^{9}$

Fonte: elaborada pelos autores.

Tabela 03 - Tipo de oração/conectivo e anteposição versus posposição

\begin{tabular}{cccccc} 
Fatores & & $\%$ & \multicolumn{2}{c}{ Aplicação/Total } \\
& Anteposição & & Posposição & Anteposição & Posposição \\
Desenvolvida & 69.3 & & 30.7 & $316 / 456$ & $140 / 456$ \\
Reduzida & 71.8 & & 28.2 & $28 / 39$ & $11 / 39$ \\
& & Totais & & $344(69.5 \%)$ & $151(30.5 \%)$
\end{tabular}

495 ocorrências

Fonte: elaborada pelos autores.

Com base no princípio de marcação (GIVÓN, 1995), hipotetizamos que as formas menos marcadas (anteposição e posposição) atuariam com mais frequência nesse contexto. Já as intercaladas, formas mais marcadas, entrariam em contextos de continuidade referencial em atendimento ao princípio da expressividade (DUBOIS; VOTRE, 2012), já que são mais integradas à nuclear que escopam. Os resultados desta primeira rodada, com percentuais muito aproximados, não nos permitem fazer afirmações categóricas. No entanto, há uma leve preferência pelas antepostas correferenciais (69.4\% contra $67.2 \%)$ do que pelas pospostas (30.6\% contra $32.8 \%)$.

\footnotetext{
${ }^{7}$ Esse princípio prevê que os constituintes costumam permanecer em seus próprios domínios e não interromper outros.

${ }^{8}$ A saber: proximidade e relevância e proximidade e escopo. Em ambos, Givón (2001a) prevê que não há tendência ao distanciamento espacial entre elementos que guardam alguma dependência (cognitiva ou sintática) entre si.

${ }^{9}$ Os demais 114 dados representam tokens excluídos deste grupo, como explicamos, já que se trata de orações sem sujeito.
} 
Parece-nos, então, que Temporais antepostas, por seu traço de guia, estabelecem também a orientação catafórica dos referentes a serem apresentados na nuclear, como em (04), o que revela uma sutil preferência pela estrutura mais marcada (orações reduzidas: $71.8 \%$ ), cuja complexidade é suavizada pela equivalência dos referentes suprimidos. No exemplo (04), a informante utiliza a Temporal anteposta reduzida teniendo novio a partir de informações cotextuais anteriormente expressas, para explicar que, nessa situação, as pessoas costumam ficar apaixonadas. Nos termos de Bakhtin (2013), essa opção expressaria melhor a individualidade do falante do que a opção correlata quando uno tiene novio (quando uma pessoa/alguém tem namorado), ainda mais considerando o tópico conversacional: relações amorosas. Além disso, o uso da reduzida evita a repetição desnecessária do sujeito uno (uma pessoa/alguém). A combinação das duas cláusulas, em um jogo discursivo, permite, inclusive, uma sobreposição de relações semânticas (FORD, 1987), entre as quais uma interpretação plausível é a de motivo:

(04) 155 E: [¿por qué] no tienes novio?

156 I: ah bueno es que realmente < realmente:>/ en mi casa ha habido muchos problemas con mis hermanos/ y <por> realmente lo pienso ahorita/ (risa)

$157 \mathrm{E}:$ ¿por qué?

158 I: ¿por qué?/ porque realmente pues < pus> yo sé que < que:>/ teniendo novio siempre uno se enamora y/ ¡siempre termina uno juntada! ¡o casada! (...)/ ¿no?.

(155 E: [por que] você não tem namorado?

156 I: ah bem é que realmente/ na minha casa houve muitos problemas com meus irmãos/ e <por> realmente penso nisso agora/ (risos)

$157 \mathrm{E}$ : por quê?

158 I: por que?/ porque realmente pois eu sei que/ tendo namorado sempre uma pessoa se apaixona e/ sempre essa pessoa termina se juntando! ou casada! (...)/ não?). (ENTREVISTA 84 - ME-307-11M-07)

Em outro polo, as pospostas manteriam as relações de coerência local não apenas com o sujeito da cláusula anterior, mas com outros referentes de sua nuclear (MANJÓN-CABEZA CRUZ et al., 2016), mitigando a consequência sintática da correferencialidade dos sujeitos, como em (05). A posposição também pode ser contexto de inserção de sujeitos pressupostos pela situação comunicativa, o que se vê em (06). Além disso, pode ser ambiente propício para 
apresentar informação totalmente nova, ou ponto de inserção de sujeito novo (SOUZA, 2001), fenômeno observado em (07):

(05) 176 I: sí/ me parece que sí/ yo la ahora < ora> la veo muy poco porque es muy po-/ para ella/ pero sí yo < yo:> la conocí des-/ cuan-/ desde antes que/ fuera arquitecta/ y ahora $<\sim$ ora $>$ es arquitecta.

(176 I: sim/ me parece que sim/ eu a agora a vejo muito pouco porque é muito pou-/ para ela/ mas sim eu a conheci des-/ quan-/ desde antes quel fosse arquiteta/ e agora é arquiteta). (ENTREVISTA 61 - ME-144-23H-01).

(06) 771 I: son este/ vientos de trescientos cincuenta kilómetros por hora

772 E: ajá

773 I: es lo que estaba yo/ escuchando ahorita cuando entraste tú.

(771 I: são é/ ventos de trezentos e cinquenta quilômetros por hora

$772 \mathrm{E}:$ aham

773 I: é o que eu estaval escutando agorinha quando você entrou). (ENTREVISTA 25 ME-009-33H-97).

(07) 409 I: (...) yo no daba crédito/ cuando/ cuando/ cuando me llegó mi carta así de la universidad y/ "bienvenida es usted universitaria"/.

(409 I: (...) eu não dava crédito/ quando/ quando/ quando chegou minha carta da universidade e/ "bem-vinda você é universitária"/). (ENTREVISTA 24 - ME-259-32M-05).

No contexto do exemplo (05), os falantes discorrem acerca de uma arquiteta, referente que, de tão acessível, é retomado pelo clítico la $(a)$ e até apagado, atendendo ao princípio de iconicidade expressão zero e previsibilidade (GIVÓN, 2001a) ${ }^{10}$ como na Temporal posposta do trecho. No dado (07), por outro lado, ainda que se apresente um referente novo e totalmente lexicalizado, a continuidade discursiva é mantida pelo possessivo ancorado mi (minha), estabelecendo uma relação anafórica com o sujeito da cláusula anterior, yo $(e u)$.

Percebemos, nesta seção, que anteposição e posposição, relacionadas, parecem não mostrar diferenças acentuadas no que diz respeito à coerência. A partir da seção seguinte, vejamos como cada uma dessas posições se comporta ao ser cotejada com a intercalação.

\footnotetext{
${ }^{10}$ Quanto mais previsível uma informação é, mais tende ao apagamento.
} 


\section{Coerência referencial e ordem de orações II - Intercalação versus anteposição}

A segunda etapa de rodadas estatísticas incluiu apenas dados de intercaladas e antepostas (445 dados), em cuja análise o programa Goldvarb considerou relevante apenas o grupo correferencialidade dos sujeitos, para o qual obtivemos pesos relativos.

Nossas hipóteses, como vimos afirmando, consistem em que intercaladas prototípicas, inseridas entre verbo e argumentos/circunstantes, observadas pelo viés da expressividade (DUBOIS; VOTRE, 2012) e dependência da marcação ao contexto (GIVÓN, 1995; 2001a), manteriam relações de coerência mais intensas que as antepostas, cujo escopo seria mais difuso. Por ser forma marcada, a intercalação atrairia opções também marcadas, como a dessentencialização da Temporal, com elementos apagados por serem recuperados na nuclear, embora em contexto menos marcado (de continuidade referencial). Por outro lado, as antepostas, menos marcadas que as intercaladas, refletiriam opções também pouco marcadas, como o uso de Temporais desenvolvidas, para retomar os referentes a que se referem. Observando os resultados sistematizados nas tabelas 04 e 05 , em sequência, notamos que essas afirmações confirmam-se apenas parcialmente:

Tabela 04 - Correferencialidade dos sujeitos e intercalação versus anteposição

\begin{tabular}{|c|c|c|c|c|c|c|}
\hline \multirow[t]{2}{*}{ Fatores } & \multicolumn{2}{|c|}{ Peso relativo } & \multicolumn{2}{|c|}{$\%$} & \multicolumn{2}{|c|}{ Aplicação/Total } \\
\hline & Intercalação & Anteposição & Intercalação & Anteposição & Intercalação & Anteposição \\
\hline Sujeitos & $0.576^{3}$ & $0.424^{3}$ & $29.4^{3}$ & 70.6 & $53 / 180$ & $127 / 180$ \\
\hline correferenciais & & & & & & \\
\hline \multirow{2}{*}{$\begin{array}{l}\text { Sujeitos não } \\
\text { correferenciais }\end{array}$} & 0.416 & 0.584 & 17.9 & 82.1 & $29 / 162$ & $133 / 162$ \\
\hline & $\begin{array}{r}\text { Significâ } \\
\mathbf{T}\end{array}$ & $\begin{array}{l}\text { ia: } 0.010 \\
\text { is }\end{array}$ & & & $\begin{array}{c}82(24 \%) \\
\mathbf{3 4 2}\end{array}$ & $\begin{array}{c}260(76 \%) \\
\text { rrências }^{11}\end{array}$ \\
\hline
\end{tabular}

Fonte: elaborada pelos autores.

Tabela 05 - Tipo de oração/conectivo e intercalação versus anteposição

\begin{tabular}{cccccc} 
Fatores & & $\%$ & \multicolumn{2}{c}{ Aplicação/Total } \\
Desenvolvida & Intercalação & & Anteposição & Intercalação & Anteposição \\
Reduzida & 22.7 & & 77.3 & $93 / 409$ & $316 / 409$ \\
& 22.2 & & 77.8 & $8 / 36$ & $28 / 36$ \\
& & Totais & & $101(22.7 \%)$ & $344(77.3 \%)$
\end{tabular}

445 ocorrências

Fonte: elaborada pelos autores.

Assim como acontece em comparação às pospostas, quanto à manifestação formal das Temporais (tabela 05), os percentuais são extremamente aproximados, sugerindo não haver associações categóricas, apenas com sutil tendência de orações antepostas reduzidas $(77.8 \%)$

${ }^{11}$ Os 103 dados restantes referem-se às cláusulas sem sujeito. 
e intercaladas desenvolvidas (22.7\%). Uma vez mais, sugere-se que a coerência das Temporais antepostas pode ser tanto global como local, sem preferências explícitas, porque também tendem a apontar para sua subsequente nuclear, compartilhando elementos, como ocorre em (04), citado. Esse fato também é apoiado pelo peso associado às antepostas correferenciais (0.424), próximo a 0.5, o que favoreceria a aplicação da regra.

Quanto à intercalação, comparada à anteposição, os resultados mostram que há maior peso probabilístico de associação dessa posição à correferencialidade (peso 0.576), como se vê em (08), no qual há manutenção dos referentes na posição de sujeito tanto da nuclear quanto da Temporal:

(08) 165 I: ahora < ora> pura química/ sí/ pero antes/ había mucha < mu:cha> gente que andaba recogiendo todo el/ el excremento de la gente que pues < pus> ahí se hi-/ se hacía del baño/ nosotros cuando vivíamos/ en < en:> en en la colonia Buenos Aires/ no teníamos baños en ese lugar donde vivíamos/ era una vecindad < vecindá $>$ / pero no había baños/...

(165 I: agora pura química/ sim/ mas antes/ havia muita gente que andava recolhendo todo o/ o excremento das pessoas que pois aí se fa-/ fazia suas necessidades/ nós quando viviamos/ na na na colônia Buenos Aires/ não tínhamos banheiros nesse lugar onde viviamos/ era uma vizinhança/ mas não havia banheiros/...). (ENTREVISTA 108 - ME-31313M-07).

No exemplo, a intercalada prototípica cuando vivíamos en la colonia Buenos Aires intercala-se entre o sujeito nosotros e o sintagma verbal no teníamos baños en ese lugar donde vivíamos. Sua coerência local é estabelecida principalmente pela continuidade referencial do sujeito, servindo de "guia/orientação referencial, já que ajuda a construir informações detalhadas sobre o referente sujeito da nuclear" (CAVALCANTE, 2020, p. 170). Quanto à marcação, as intercaladas têm uma leve tendência de expressão por meio de orações desenvolvidas (22.7\% ao invés de $22.2 \%$ das reduzidas), o que acreditamos ser um mecanismo menos complexo para suavizar sua inerente complexidade (DUBOIS; VOTRE, 2012; CAVALCANTE, 2020).

Feitas as correlações entre intercaladas e antepostas, vejamos como as intercaladas se comportam ao serem cotejadas com as pospostas. 


\section{Coerência referencial e ordem de orações III - Posposição versus intercalação}

As rodadas estatísticas que relacionaram posposição e intercalação, cujos resultados vemos nas tabelas 06 e 07, contaram com 252 dados, e novamente o programa estatístico selecionou o grupo correferencialidade. Até aqui podemos perceber que, nas três análises realizadas, sempre que o grupo das intercaladas era inserido, mostrava associação relevante com a correferencialidade.

Tabela 06 - Tipo de oração e posposição versus intercalação

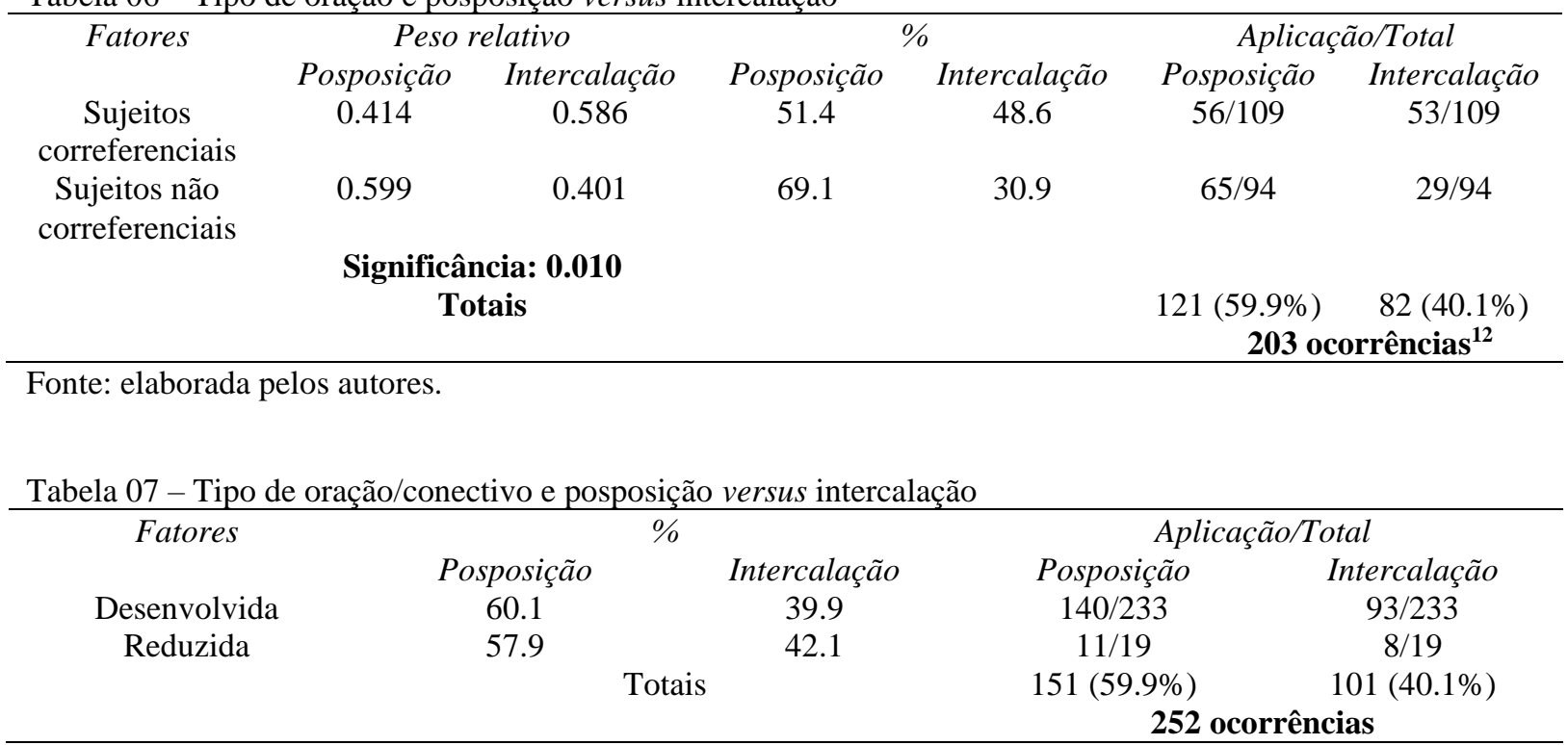

Fonte: elaborada pelos autores.

Como dito, hipotetizamos que pospostas e intercaladas manteriam relações de coerência mais local que antepostas, e que as intercaladas tenderiam a refletir procedimentos marcados, como a dessentencialização da oração, equilibrando o efeito dos princípios de marcação e expressividade. Quanto a este último aspecto, vimos, na seção anterior, que, em contraste com as antepostas, as intercaladas tendem sutilmente à expressão por meio de orações desenvolvidas, ao passo que, em oposição às pospostas, denotam mais mecanismos de integração à sua nuclear, como mostram as últimas tabelas apresentadas.

O que se pode perceber é que, em um continuиm discursivo, as intercaladas apresentam maior tendência a facilitar a coerência referencial. Isso se comprova pela correferencialidade de seus sujeitos (peso 0.586), como em (09), também por tendência à redução de seus elementos $(42.1 \%)$ em comparação à posposição, contexto que seria favorável à continuidade discursiva. No exemplo a seguir, o falante utiliza a intercalada desde que tengo trece años para narrar fatos de sua própria vida:

${ }^{12}$ Os 49 dados que faltam dizem respeito às cláusulas com sujeito inexistente. 
(09) 104 I: (...) yo yo me vine de/ doce años/ y de trece años aquí < aquí:>/ estoy desde que tengo trece años aquí [trabajando]. (eu eu vim aos/ doze anos/ e aos treze anos aqui/ estou desde que tenho treze anos aqui [trabalhando]). (ENTREVISTA 37 - ME04921H-99)

A partir dos resultados das variáveis correferencialidade e tipo de oração em relação à ordem de cláusulas, estabelecemos, na seção seguinte, um continuum de mecanismos de coerência referencial.

\section{Coerência referencial e ordem de orações IV - um continuum}

Fazendo um cruzamento entre ordem, tipo das Temporais e correferencialidade, podemos constatar alguns meios de como funciona a coerência referencial. Segundo os resultados da tabela 08 e do quadro 01, a seguir, percebemos que a correferencialidade perpassa os distintos tipos e posições da Temporal, embora com preferências:

Tabela 08 - Cruzamento entre ordem da Temporal, tipo de oração e correferencialidade dos sujeitos

\begin{tabular}{|c|c|c|}
\hline & Sujeitos correferenciais & Sujeitos não-correferenciais \\
\hline Anteposta Reduzida & $52,17 \%(12 / 23)$ & $47,83 \%(11 / 23)$ \\
\hline Anteposta Desenvolvida & $48,52 \%(115 / 237)$ & $51,48 \%(122 / 237)$ \\
\hline Intercalada Reduzida & $57,14 \%(4 / 7)$ & $42,86 \%(3 / 7)$ \\
\hline Intercalada Desenvolvida & $65,33 \%(49 / 75)$ & $34,67 \%(26 / 75)$ \\
\hline Posposta Reduzida & $57,14 \%(4 / 7)$ & $42,86 \%(3 / 7)$ \\
\hline Posposta Desenvolvida & $45,61 \%(52 / 114)$ & $54,39 \%(62 / 114)$ \\
\hline
\end{tabular}

Fonte: elaborada pelos autores.

Quadro 01 - Cruzamento entre ordem da Temporal, tipo de oração e correferencialidade dos sujeitos

\begin{tabular}{|c|c|c|c|}
\hline & Anteposta & Intercalada & Posposta \\
\hline Temporal reduzida & Sujeitos correferenciais & Sujeitos correferenciais & Sujeitos correferenciais \\
\hline $\begin{array}{c}\text { Temporal } \\
\text { desenvolvida }\end{array}$ & Sujeitos não-correferenciais & Sujeitos correferenciais & Sujeitos não-correferenciais \\
\hline
\end{tabular}

Fonte: elaborado pelos autores.

Os cruzamentos realizados evidenciam que as intercaladas, em ambas realizações formais (com preferência pelas desenvolvidas), junto às pospostas reduzidas, constituem as formas menos marcadas para a continuidade referencial. A essas estruturas, seguem-se, nessa ordem, as antepostas reduzidas, as desenvolvidas, e as pospostas desse mesmo tipo. Permitimo-nos, portanto, postular o seguinte continuum de coerência referencial a partir das variáveis aqui analisadas: 
Figura 01 - continuum de continuidade referencial

$\mid \begin{gathered}\text { Contexto de maior continuidade referencial } \\ \text { Temporal intercalada desenvolvida } \\ \text { Temporal intercalada reduzida/Temporal posposta reduzida } \\ \text { Temporal anteposta reduzida } \\ \text { Temporal anteposta desenvolvida } \\ \text { Temporal posposta desenvolvida } \\ \text { Contexto de menor continuidade referencial }\end{gathered}$

Fonte: elaborada pelos autores.

No topo da escala, ficam as intercaladas, que equilibram sua complexidade estrutural por meio de orações desenvolvidas, servindo a motivações relacionadas à expressividade (DUBOIS; VOTRE, 2012). Em seguida, figuram as reduzidas, que marcam sua continuidade por meio da perda de elementos compartilhados, das intercaladas às antepostas, passando pelas pospostas, retomando referentes mencionados na cláusula nuclear. Logo depois, vemos as antepostas desenvolvidas, que direcionam a interpretação da sentença que virá. Na base da escala, estão as pospostas desenvolvidas, servindo à apresentação de informações novas ou mantendo a continuidade por meio de elementos pressupostos pela situação comunicativa.

\section{Conclusões}

Neste artigo, analisamos o fenômeno da coerência referencial (GIVÓN, 1995; 2001b) correlacionando-o com meios sintáticos, entre os quais a posição das orações, seu tipo (desenvolvida, reduzida) e compartilhamento de sujeito com suas nucleares (correferencialidade). Tendo por viés a abordagem funcionalista, que defende a combinação de orações como questão de grau (HAIMAN; THOMPSON, 1984; HOPPER; TRAUGOTT, 2003; GIVÓN, 2001b), voltamo-nos para a descrição das Cláusulas Hipotáticas Temporais no Espanhol mexicano oral e testamos as hipóteses de Givón (1995; 2001b) no que se refere à maior continuidade referencial de sentenças mais integradas às cláusulas que escopam.

Nossos resultados mostram a atuação do princípio de marcação e sua dependência ao contexto (GIVÓN, 1995; 2001a) e do princípio de expressividade (DUBOIS; VOTRE, 2012). As orações às margens (anteposição e posposição) não apresentam, quando cotejadas entre si, acentuadas diferenças no que diz respeito à correferencialidade. Contudo, em comparação com o mecanismo de intercalação, essas posições não motivam correferencialidade. Alertamos, no entanto, para o fato de que as afirmações aqui expostas não podem ser tomadas como categóricas, porque as diferenças percentuais se apresentaram de maneira sutil; e os pesos relativos, próximos ao ponto neutro (0.5). Entretanto, pudemos mostrar que a língua 
revela motivações comunicativas distintas por meio dos modos de posicionar uma cláusula temporal ao longo do período em que se insere.

Em perspectiva escalar, percebemos que os contextos de maior continuidade referencial têm como expressão formal não marcada as intercaladas desenvolvidas, seguidas desse mesmo tipo e dos demais padrões em forma reduzida. Essas estruturas se opõem às antepostas e pospostas desenvolvidas, que atuam em contexto de menor continuidade referencial, o que, no primeiro caso, parece apontar para relações anafóricas, e, no segundo caso, para expressão de sujeitos novos, pressupostos pela situação comunicativa ou não correferenciais aos da nuclear.

Os resultados decorrentes desta pesquisa corroboram pesquisas anteriores sobre o espanhol mexicano, dentre as quais as de Cavalcante (2015, 2017, 2020). Além disso, permitem-nos estabelecer similaridades com outras variedades do espanhol, cujos achados se encontram, por exemplo, em Silva-Corvalán (2003) e Manjón-Cabeza Cruz et al. (2016). Nossas descobertas expõem, ainda, uma aproximação aos mecanismos de articular orações em outras línguas, tais como o português e o inglês, uma vez que as tendências são semelhantes às observadas em Decat (2001), Souza (2001), Haiman; Thompson (1984), entre outros.

\section{Referências}

ANDERSEN, H. Markedness and the theory of linguistic change. ANDERSEN, H. (Ed.). Actualization (Current Issues in Linguistic Theory 219) 21-57. Amsterdam-Philadelphia: Benjamins, 2001. p. 21-57.

BAKHTIN, M. Questões de estilística no ensino da língua. Tradução, posfácio e notas de Sheila Grillo e Ekaterina Vólkova Américo. São Paulo: Editora 34, 2013.

CAVALCANTE, S. A. de S. Análise sociofuncionalista da ordenação de cláusulas hipotáticas adverbiais temporais no Espanhol mexicano oral. 2015. 182 f. Dissertação (Mestrado em Linguística) - Programa de Pós-Graduação em Linguística, Universidade Federal do Ceará, Fortaleza, 2015. Disponível em: http://www.repositorio.ufc.br/handle/riufc/12620?mode=full. Acesso em: 10 mai. 2020.

CAVALCANTE, S. A. de S. Análise das Orações Temporais reduzidas em Espanhol pelo viés do princípio de marcação. Cadernos de Letras da UFF, Niterói, v. 27, n. 55, p. 83-107, 2017. Disponível em:

http://www.cadernosdeletras.uff.br/index.php/cadernosdeletras/article/view/504. Acesso em: 10 mai. 2020.

CAVALCANTE, S. A. de S. Efeitos prototípicos da intercalação de Cláusulas Hipotáticas Circunstanciais Temporais no Espanhol mexicano oral. 2020. Tese (Doutorado em Linguística) - Centro de Humanidades, Programa de Pós-Graduação em Linguística, Universidade Federal Ceará, Fortaleza, 2020. Disponível em: http://repositorio.ufc.br/handle/riufc/51477. Acesso em: 10 mai. 2020. 
DECAT, M. B. N. A articulação hipotática adverbial no português em uso. In: DECAT, M. B. N.; SARAIVA, M. E. F.; BITTENCOURT, V. O.; LIBERATO, Y. G. (Orgs.). Aspectos da gramática do português: uma abordagem funcionalista. 1. ed. Campinas: Mercado de Letras, 2001. p. 103-166.

DU BOIS, J. W. The discourse basis of ergativity. Language, Baltimore, v. 63, p. 805-855, 1987.

DUBOIS, S.; VOTRE, S. J. Análise modular e princípios subjacentes do funcionalismo linguístico. In: VOTRE, S. J. (Org.). A construção da gramática. Niterói: Editora da UFF, 2012. p. 49-71.

FORD, C. Overlapping relations in text structure. In: ANNUAL MEETING OF THE PACIFIC LINGUISTICS CONFERENCE, 2., 1986, Oregon. Proceedings... DELANCEY, S.; TOMLIN, R. S. (Eds.). Oregon: University of Oregon, Dept. of Linguistics, 1987.

FURTADO DA CUNHA, M. A.; COSTA, M. A.; CEZARIO, M. M. Pressupostos teóricos fundamentais. In: FURTADO DA CUNHA, M. A.; OLIVEIRA, M. Rios de;

MARTELOTTA, M. E. (Orgs.). Linguística funcional: teoria e prática. Rio de Janeiro: Faperj/DP\&A, 2003. p. 29-55.

GIL, A. C. Métodos e técnicas de pesquisa social. São Paulo: Atlas, 2008.

GIVÓN, T. Functionalism and grammar. Philadelphia: J. Benjamins, 1995.

GIVÓN, T. Syntax: An Introduction - Volume I. Amsterdam: J. Benjamins, 2001a.

GIVÓN, T. Syntax: An Introduction - Volume II. Amsterdam/Philadelphia: John Benjamins Publishing Company, $2001 b$.

GUY, G. R.; ZILLES, A. Sociolinguística Quantitativa: instrumental de análise. São Paulo: Parábola, 2007.

HAIMAN, J.; THOMPSON, S. A. Subordination in universal grammar. In: ANNUAL MEETING OF BERKELEY LINGUISTICS SOCIETY, 10, 1984, Berkeley. Proceedings... Berkeley: Berkeley Linguistics Society, 1984.

HALLIDAY, M. A. K. An introduction to funcional grammar. 3. ed. Revised by Christian M. I. M. Matthiessen. London: Hodder Education, 2004[1985].

HOPPER, P.; TRAUGOTT, E. C. Grammaticalization. Cambridge: Cambridge University Press, 2003.

KOCH, I. V.; TRAVAGLIA, L. C. A coerência textual. 18. ed. São Paulo: Contexto, 2015.

LEHMANN, C. Towards a typology of clause linkage. In: HAIMAN, J.; THOMPSON, S. A. Clause combining in grammar and discourse. Amsterdam/Philadelphia: John Benjamins Publishing Company, 1988. p. 181-225. 
MACAMBIRA, J. R. A estrutura da oração reduzida. Fortaleza: Imprensa Universitária da Universidade Federal do Ceará, 1971.

MANJÓN-CABEZA CRUZ, A.; POSE FUREST, F.; SÁNCHEZ GARCÍA, F. J. Factores determinantes en la expresión del sujeto pronominal en el corpus PRESEEA de Granada.

Boletín de Filología, Tomo LI, n. 2, p. 181-207, 2016. Disponível em:

https://scielo.conicyt.cl/scielo.php?script=sci_abstract\&pid=S0718-

93032016000200007\&lng=es\&nrm=iso. Acesso em: 10 mai. 2020.

OLIVARES PARDO, M. A. El tiempo y los tiempos en las subordinadas temporales. Estudio de casos. In: FIGUEROLA CABROL, M. C.; PARRA, M.; SOLÀ, P. (Eds.). La lingüística francesa en el nuevo milenio. Lleida: Editorial Milenio, 2002. p. 541-550.

PILAR GARCÉS, María. La oración compuesta en español, estructuras y nexos. Madrid: Verbum, 1994.

RICHARDSON, R. J. et al. Pesquisa social: métodos e técnicas. 3. ed. 14. reimpr. São Paulo: Atlas, 2012.

SARDINHA, T. B. Linguística de Corpus. Barueri, SP: Manole, 2004.

SILVA-CORVALÁN, C. Otra mirada a la expresión del sujeto como variable sintáctica. In: MORENO FERNÁNDEZ, F. et al. Lengua, variación y contexto. Estudios dedicados a Humberto López Morales - v. II. Madrid: Arco/Libros, 2003. p. 849-860. Disponível em: http://smjegupr.net/wp-content/uploads/2012/08/Otra-mirada-a-la-expresion-del-sujeto-comovariable-sint\%C3\%A1ctica.pdf. Acesso em: 10 mai. 2020.

SOUZA, M. S. C. de. O papel discursivo e coesivo das orações temporais. In: NEVES, M. H. de M. (Org.). Descrição do Português: definindo rumos de pesquisa. São Paulo: Cultura Acadêmica Editora, 2001. p. 67-78.

\section{Sobre os autores}

Sávio André de Souza Cavalcante (Orcid iD: http://orcid.org/0000-0001-5152-6924)

Doutor e mestre em Linguística Universidade Federal do Ceará (UFC); graduado em Letras - Português/Espanhol pela mesma instituição. É professor de Língua Espanhola no Instituto Federal de Educação, Ciência e Tecnologia do Ceará (IFCE) e professor tutor do Instituto UFC Virtual / Universidade Aberta do Brasil, nos cursos de graduação Letras Português e Letras - Espanhol, na modalidade a distância.

\section{Márluce Coan (Orcid iD: http://orcid.org/0000-0001-7809-8624)}

Doutora e mestra em Linguística pela Universidade Federal de Santa Catarina (UFSC); graduada em Letras pela mesma instituição. É professora do Departamento de Letras Vernáculas e do Programa de Pós-Graduação em Linguística da Universidade Federal do Ceará (UFC). Bolsista Produtividade em Pesquisa do CNPq, nível 2.

Recebido em junho de 2020.

Aprovado em agosto de 2020. 